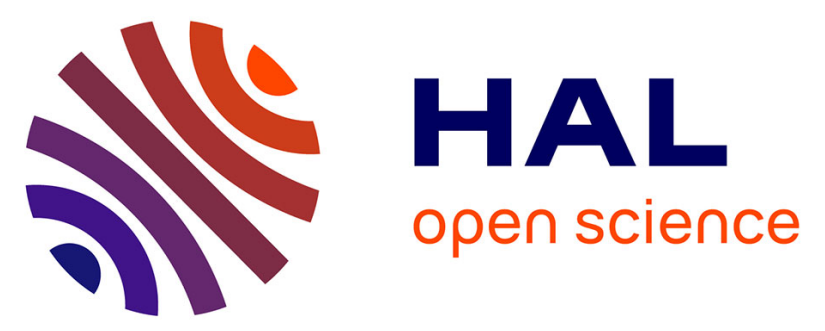

\title{
Combinatorial MAPLE deposition of antimicrobial orthopedic maps fabricated from chitosan and biomimetic apatite powders
}

Anita Ioana Visan, George E. Stan, Carmen Ristoscu, Gianina Popescu-Pelin, Mihai Sopronyi, C. Besleaga, Catalin Luculescu, Mariana Carmen Chifiriuc, M.D. Hussien, Olivier Marsan, et al.

\section{To cite this version:}

Anita Ioana Visan, George E. Stan, Carmen Ristoscu, Gianina Popescu-Pelin, Mihai Sopronyi, et al.. Combinatorial MAPLE deposition of antimicrobial orthopedic maps fabricated from chitosan and biomimetic apatite powders. International Journal of Pharmaceutics, 2016, vol. $511\left(\mathrm{n}^{\circ} 1\right)$, pp. 505-515. 10.1016/j.ijpharm.2016.07.015 . hal-01445327

\section{HAL Id: hal-01445327 \\ https://hal.science/hal-01445327}

Submitted on 24 Jan 2017

HAL is a multi-disciplinary open access archive for the deposit and dissemination of scientific research documents, whether they are published or not. The documents may come from teaching and research institutions in France or abroad, or from public or private research centers.
L'archive ouverte pluridisciplinaire HAL, est destinée au dépôt et à la diffusion de documents scientifiques de niveau recherche, publiés ou non, émanant des établissements d'enseignement et de recherche français ou étrangers, des laboratoires publics ou privés. 


\section{OATAO \\ Open Archive Toulouse Archive Ouverte}

\section{Open Archive TOULOUSE Archive Ouverte (OATAO)}

OATAO is an open access repository that collects the work of Toulouse researchers and makes it freely available over the web where possible.

This is an author-deposited version published in : http://oatao.univ-toulouse.fr/ Eprints ID : 16547

To link to this article : DOI:10.1016/j.ijpharm.2016.07.015 URL : http://dx.doi.org/10.1016/j.ijpharm.2016.07.015

To cite this version : Visan, Anita Ioana and Stan, George E. and Ristoscu, Carmen and Popescu-Pelin, Gianina and Sopronyi, Mihai and Besleaga, C. and Luculescu, Catalin and Chifiriuc, Mariana Carmen and Hussien, M.D. and Marsan, Olivier and Kergourlay, Emmanuelle and Grossin, David and Brouillet, Fabien and Mihailescu, Ion N. Combinatorial MAPLE deposition of antimicrobial orthopedic maps fabricated from chitosan and biomimetic apatite powders. (2016) International Journal of Pharmaceutics, vol. 511 ( $\left.\mathrm{n}^{\circ} 1\right)$. pp. 505-515. ISSN 0378-5173

Any correspondence concerning this service should be sent to the repository administrator: staff-oatao@listes-diff.inp-toulouse.fr 


\title{
Combinatorial MAPLE deposition of antimicrobial orthopedic maps fabricated from chitosan and biomimetic apatite powders
}

\author{
A. Visan ${ }^{\mathrm{a}}$, G.E. Stan ${ }^{\mathrm{b}}$, C. Ristoscu ${ }^{\mathrm{a}}$, G. Popescu-Pelin ${ }^{\mathrm{a}}$, M. Sopronyi ${ }^{\mathrm{a}}$, C. Besleaga ${ }^{\mathrm{b}}$, \\ C. Luculescu ${ }^{\mathrm{a}}$, M.C. Chifiriuc ${ }^{\mathrm{c}, \mathrm{d}}$, M.D. Hussien ${ }^{\mathrm{c}, \mathrm{d}}$, O. Marsan ${ }^{\mathrm{e}}$, E. Kergourlay ${ }^{\mathrm{e}}$, D. Grossin ${ }^{\mathrm{e}}$, \\ F. Brouillet ${ }^{\mathrm{e}}$, I.N. Mihailescu ${ }^{\mathrm{a}, *}$ \\ a National Institute for Laser, Plasma and Radiation Physics, 077125 Magurele-Ilfov, Romania \\ ${ }^{\mathrm{b}}$ National Institute of Materials Physics, 077125 Magurele-Ilfov, Romania \\ ${ }^{\mathrm{c}}$ Department of Microbiology, Faculty of Biology, University of Bucharest, 060101 Bucharest, Romania \\ d Earth, Environmental and Life Sciences Division, Research Institute of the University of Bucharest, 77206 Bucharest, Romania \\ e University of Toulouse, CIRIMAT, UPS - INPT - CNRS, ENSIACET, 4 Allée Emile Monso, 31030 Toulouse Cedex 4, France
}

Keywords:

Combinatorial MAPLE

Chitosan

Biomimetic apatite

Thin films

Antimicrobial action

S. aureus

E. coli.
Chitosan/biomimetic apatite thin films were grown in mild conditions of temperature and pressure by Combinatorial Matrix-Assisted Pulsed Laser Evaporation on Ti, Si or glass substrates. Compositional gradients were obtained by simultaneous laser vaporization of the two distinct material targets. A KrF* excimer $\left(\lambda=248 \mathrm{~nm}, \tau_{\mathrm{FWHM}}=25 \mathrm{~ns}\right)$ laser source was used in all experiments. The nature and surface composition of deposited materials and the spatial distribution of constituents were studied by SEM, EDS, AFM, GIXRD, FTIR, micro-Raman, and XPS. The antimicrobial efficiency of the chitosan/biomimetic apatite layers against Staphylococcus aureus and Escherichia coli strains was interrogated by viable cell count assay.

The obtained thin films were XRD amorphous and exhibited a morphology characteristic to the laser deposited structures composed of nanometric round shaped grains. The surface roughness has progressively increased with chitosan concentration. FTIR, EDS and XPS analyses indicated that the composition of the BmAp-CHT C-MAPLE composite films gradually modified from pure apatite to chitosan.

The bioevaluation tests indicated that $S$. aureus biofilm is more susceptible to the action of chitosanrich areas of the films, whilst the $E$. coli biofilm proved more sensible to areas containing less chitosan.

The best compromise should therefore go, in our opinion, to zones with intermediate-to-high chitosan concentration which can assure a large spectrum of antimicrobial protection concomitantly with a significant enhancement of osseointegration, favored by the presence of biomimetic hydroxyapatite.

\section{Introduction}

Natural polymers are currently employed to obtain tailored systems for drug passive/active targeting in order to decrease the incidence of the side effects (Kim et al., 2008). The natural polymers exhibit the major advantage of biodegradability inside the human body, not requiring removal or additional manipulation (Nair and Laurencin, 2006). Due to their excellent biocompatibility and cost-effectiveness they can be used as pharmaceutical excipients (Chifiriuc et al., 2014).

\footnotetext{
* Corresponding author.

E-mail address: ion.mihailescu@inflpr.ro (I.N. Mihailescu).
}

Among natural polymers used for drug delivery, chitosan (CHT) is a highly biodegradable, non-toxic and biocompatible cationic polysaccharide synthesized from chitin by alkaline deacetylation (Vllasaliu et al., 2012; Sogias et al., 2012; Derakhshandeh and Fathi, 2012; Gan and Wang, 2007). The chitosan potential to be used as an antimicrobial agent (Martins et al., 2014), was stressed upon together with delivery of antibiotics, such as beta-lactams (e.g., penicillins, cephalosporins), aminoglycosides and daptomycin (Noel et al., 2008; Grumezescu et al., 2012; Grumezescu et al., 2011).

Nevertheless, CHT application in anti-infective strategies is limited because of its low solubility at neutral or basic $\mathrm{pH}$. For this reason, the focus has been recently moved to the design of 
antimicrobial films consisting of CHT and its derivatives. They demonstrated excellent inhibitory activity against a wide spectrum of Gram-positive and Gram-negative bacteria, including food contaminants (Kong et al., 2010; Dutta et al., 2009; Leceta et al., 2013; Dai et al., 2011).

Recent studies revealed the potential of CHT/hydroxyapatite (HA) composites to be used as coatings on titanium surface in order to increase the osseointegration capacity of bone implants ( $\mathrm{Ma}$ et al., 2014; Li et al., 2015). There exist however, a few studies only, aiming to evaluate the anti-biofilm activity of such coatings, an aspect of key importance for the prevention and control of implant-associated infections.

Many authors have reported the preparation of mixtures of calcium phosphates (CaP) and CHT in the form of powders (Yoshida et al., 2004), membranes (Ito et al., 1999), scaffolds (Zhang and Zhang, 2002), or microspheres (Sivakumar et al., 2002). Nevertheless, only few publications were focused on developing procedures allowing the concomitant preparation of a composite material containing the two components, which is expected to ensure a more intimate contact between them (Hu et al., 2004; Davidenko et al., 2010; Thein-Han and Misra, 2009).

CHT-CaP composite films have been synthesized by several methods like: pulsed electrochemical deposition (Jia et al., 2016a), electrophoretic deposition (Zhong et al., 2015), plasma spraying (Song et al., 2011), or co-precipitation method (Peña et al., 2006).

On the other hand, over the past decades, laser techniques proved a high potential for the fabrication of antimicrobial coatings for orthopedic implants for medical applications such as the bone tissue replacement or treatment of osteoporosis or osteolytic tumors (Jia et al., 2016b; Simchi et al., 2011).

Furthermore, the laser-based technologies are exhibiting a lot of advantages, as they allow for the fabrication of a wide-range of different biomaterials, with a fairly uniform spreading of material over rather large areas, controlled film thickness (with an accuracy of $1 \AA$ ), good adhesion to substrate (Blind et al., 2005; Duta et al., 2013; Mihailescu et al., 2016), and specific surface properties (Sima and Mihailescu, 2013). Moreover, these deposition methods imply a low material consumption, and ensure the stoichiometry preservation of the growing films (Eason, 2006; Yu et al., 2014; Cristescu et al., 2012). In the same time, remarkable efforts were recently paid to the development by combinatorial processing of new biomaterials with innovative properties. Usually, the fabrication of a composite layer is carried out by premixing of biopolymer solutions followed by heating of coating (Meredith et al., 2000) or film casting/solvent evaporation (Li et al., 2012). The combinatorial technology for the blending of two different biomaterials (Torricelli et al., 2015; Sima et al., 2014; Axente et al., 2014; Sima et al., 2012) is based on Matrix-Assisted Pulsed Laser Evaporation (MAPLE) method. This newly developed technique - Combinatorial-MAPLE (C-MAPLE) - stands for a simple, single step, fabrication route which can easily limit the time of manipulation and biomaterials consumption.

The aim of this study was to synthesize thin coatings containing natural biopolymer chitosan combined with biomimetic apatite (Eichert et al., 2007; Grossin et al., 2010; Visan et al., 2014) directly on titanium implants by C-MAPLE technique.

As known, a biomaterial used for bone substitution should possess a set of ineluctable properties. They are:

(i) An identical chemical composition to the natural bone (which is a complex structure of organic and inorganic materials (Dorozhkin, 2009)). For this purpose, the nonstoichiometric biomimetic apatite (BmAp) (Eichert et al., 2007; Grossin et al., 2010; Visan et al., 2014), has been used as model for the basic constituent of the inorganic part of the bone, and chitosan (CHT), a natural biopolymer, with a similar chemical structure to the glycosaminoglycan, the prevalent extracellular matrix of the bone and cartilage, as the organic phase of bone (Vllasaliu et al., 2012).

(ii) A good mechanical strength. The coatings were therefore deposited on titanium (Ti) medical implants, thus harmoniously combing the excellent mechanical features of Ti with the biomimetics of the organic-inorganic biofunctional layers (Agarwal and García, 2015). This will confer stability and reliability to the medical device assembly.

(iii) Biocompatibility. From this point of view, both CHT and BmAp exhibit excellent cytocompatibility and remarkable osteoconductive properties, respectively (Song et al., 2011; VandeVord et al., 2002).

(iv) Resistance to microbial colonization, particularly during the osseointegration period. In this regard, CHT shows a higher antibacterial activity against a broad spectrum of microbial agents (Lee et al., 2009). It is therefore expected that the composite structures of polymer ( $\mathrm{CHT}) /$ ceramic (BmAp) will exhibit a double function: antimicrobial protection and enhancement of osteoblast cell proliferation, opening new promising opportunities for developing a new generation of orthopedic implants.

To the best of our knowledge, this is the first attempt to synthesize a composition gradient between $\mathrm{CHT}$ and BmAp by laser co-evaporation of the two distinct cryogenic targets followed by a co-deposition process.

\section{Materials and methods}

\subsection{Materials}

CHT with a low molecular weight was purchased from SigmaAldrich, while the biomimetic apatite powder, with a particle size $<25 \mu \mathrm{m}$, was prepared by the co-precipitation method in accordance with a previously described protocol (Visan et al., 2014). Solutions consisting of $2 \%$ CHT and $1 \%$ BmAp in deionized water were prepared. All target solutions were poured into a copper target holder, pre-cooled at $173 \mathrm{~K}$, and subsequently frozen by immersion in liquid nitrogen for $15 \mathrm{~min}$.

\subsection{C-MAPLE deposition process}

C-MAPLE technique was used for the fabrication of a compositional map of the two compounds (i.e., CHT and BmAp). In the experiments, an excimer laser source $\left(\mathrm{KrF}^{*}, \lambda=248 \mathrm{~nm}, \tau_{\mathrm{FWHM}}=\right.$ $25 \mathrm{~ns}$ ) operated at $10 \mathrm{~Hz}$ frequency repetition rate was used for the cryogenic targets evaporation. As deposition substrates were used: $12 \mathrm{~mm}$ diameter Ti (grade 4) disks, Si wafers or glass slides. In order to obtain uniform coatings, the targets were permanently rotated $(80 \mathrm{rpm})$. This way, the drilling was avoided and the expulsion of materials is promoted in a proper way, ensuring a uniform deposition. In C-MAPLE experiments, the two targets (e.g., CHT and $\mathrm{BmAp}$ ) were simultaneously evaporated by the laser beam, which was divided into two beams (Fig. 1a) by an optical splitter. The two beams were focused in parallel onto the surface of each target, containing the frozen solutions to be irradiated.

The used method allows to combine two different biomaterials and to select the best solvent/concentration to be used for the two compounds. In our experiments, after preliminary studies, deionized water was chosen as solvent and the concentrations of 1 and 2 wt.\% were used for CHT and BmAp substances, respectively. We also performed a parametric study on optimum laser energy $(70,100,120$ and $150 \mathrm{~mJ})$ for which the materials are deposited unaltered. The selected laser energy was: $100 \mathrm{~mJ}$ in the case of CHT target and of $70 \mathrm{~mJ}$ for the BmAp one. 


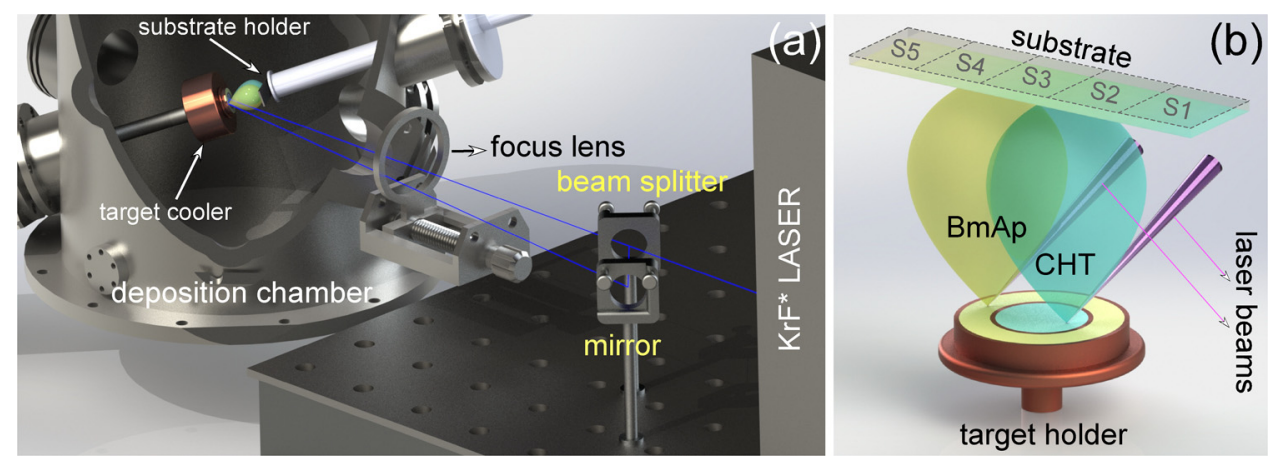

Fig. 1. (a) C-MAPLE experimental setup. (b) Schematic representation of the coating with compositional gradient obtained by C-MAPLE.

In a configuration with a distance between the plasma centers of $30 \mathrm{~mm}$, one obtains a $60 \mathrm{~mm}$ long deposition with edges consisting of CHT and of BmAP only, and in-between discrete areas of CHT-BmAp blended compositions. The soft mixing of the two compounds evaporated from the two distinct targets can result in the deposition of a continuous and uniform film with a composition gradient, as depicted schematically in Fig. $1 \mathrm{~b}$.

The coated samples areas deposited onto the substrate array composed of five consecutive $12 \mathrm{~mm}$ Ti disks are further denoted S1 to S5; where S1 stands for the coating area having CHT as major component, S5 represents the coating area with richer content of $\mathrm{BmAp} . \mathrm{S} 2 \rightarrow \mathrm{S} 3 \rightarrow \mathrm{S} 4$ series indicates blended coating areas with decreasing CHT/BmAp ratios. For comparison reasons, simple CHT and BmAp films have been also deposited on the same type of substrates.

Depending on the laser parameters and polymeric-ceramic composition, the thickness of C-MAPLE coating, as determined by profilometry, was in the (1-2) $\mu \mathrm{m}$ range. The obtained thickness value was calculated as the average of three independent measurements.

\subsection{Physico-chemical characterization techniques}

(a) The general surface morphology of the deposited films was investigated by scanning electron microscopy (SEM) using a Hitachi S3400 Electron Microscope. The investigations were carried out in high vacuum at an acceleration voltage of $25 \mathrm{kV}$. The samples were coated with a thin Au film in order to reduce electrical charging during analysis.

(b) Further surface morphology insightful analysis has been performed in multiple areas of the blended coating by atomic force microscopy (AFM) in non-contact mode using an NT-MDT NTEGRA Probe NanoLaboratory system (NT-MDT NSG01 cantilever with tip radius of $10 \mathrm{~nm}$ ).

(c) Compositional analyses have been carried out by energydispersive X-ray spectroscopy (EDS) with SiLi EDAX Inc. detector (attachment of SEM apparatus).

(d) The structure of the simple CHT and BmAp MAPLE films was investigated by grazing incidence X-ray diffraction (GIXRD) using a Bruker D8 Advance diffractometer, in parallel beam setting, with $\mathrm{Cu} K \alpha(\lambda=1.5418 \AA)$ incident radiation. The incidence angle was set to $2^{\circ}$, and the scattered intensity was scanned within the $2 \theta$ range $(20-45)^{\circ}$, with a step size of $0.04^{\circ}$, and $40 \mathrm{~s}$ per step.

(e) Fourier transform infrared (FTIR) spectroscopy was used for analyzing the functional groups present in the C-MAPLE coating deposited on the $60 \mathrm{~mm}$ long Ti plate. The analyses were performed in different regions of the films, at separation distances of $\sim 2 \mathrm{~mm}$, with a Perkin Elmer Spectrum BX II spectrometer, in attenuated total reflection mode (ATR) using a Pike-MIRacle diamond head of $1.8 \mathrm{~mm}$ diameter. The spectra were collected in the range $4000-550 \mathrm{~cm}^{-1}$, by recording 128 individual scans at a resolution of $4 \mathrm{~cm}^{-1}$.

(f) The micro-Raman analysis of the starting powders and CMAPLE coatings has been performed with a Horiba Jobin Yvon Labram HR 800 spectrometer, in the $3800-100 \mathrm{~cm}^{-1}$ range. A laser excitation wavelength of $632.8 \mathrm{~nm}$ has been used in the case of powders. The C-MAPLE film deposited on the $60 \mathrm{~mm}$ long glass plate has been exposed to a continuous laser radiation provided by an Argon diode laser at $532 \mathrm{~nm}$ with a power of $12 \mathrm{~mW}$. The samples were placed in an Olympus BX 41 microscope and focused by an objective $50 \mathrm{x}$ with long distance numerical aperture of 0.75 , which gives the system a lateral resolution of $1 \mu \mathrm{m}$ and an axial resolution of $4.5 \mu \mathrm{m}$. The mappings were carried out using an XYZ motorized stage with an accuracy of $0.1 \mu \mathrm{m}$. The size of mapping areas was of $(80 \times 100) \mu \mathrm{m}^{2}$, with a measurement pitch of $1 \mu \mathrm{m}$.

The spectrum of each point was acquired through a 600 line/ mm grating, with a spectral resolution of $1 \mathrm{~cm}^{-1}$ and collected with a quantum well detector cooled to $-60^{\circ} \mathrm{C}$ double Pelletier's effect (Synapse CCD). A certified silicon standard allowed calibrating frequency equipment using with the first order of silicon line at $520.7 \mathrm{~cm}^{-1}$. Each point on the map was acquired with an integration time of $20 \mathrm{~s}$ and 1 accumulation. A baseline correction processing was performed using the Labspec 5 software.

- X-ray photoelectron spectroscopy (XPS) analysis was performed using a Thermo Scientific K-Alpha apparatus. Photoemission spectra are recorded using $\mathrm{Al} \mathrm{K} \alpha=1486.71 \mathrm{eV}$ monochromatized radiation. The $\mathrm{X}$-ray spot diameter on the sample surface is of $400 \mu \mathrm{m}$. The pass energy was fixed at $30 \mathrm{eV}$ for narrow scan, and at $170 \mathrm{eV}$ for survey scans. The background signal was removed using the Shirley method. Atomic concentrations were determined from photoelectron peak areas using the atomic sensitivity factors, taking into account the transmission function of the analyzer. Photoelectron peaks were analyzed and deconvoluted using a Lorentzian/Gaussian $(\mathrm{L} / \mathrm{G}=30)$ peak fitting.

\subsection{Antimicrobial assays}

\subsubsection{Microbial strains and growth conditions}

Staphylococcus aureus ATCC 6538 and Escherichia coli ATCC 8739 were purchased from American Type Culture Collection (ATCC, US). Glycerol stocks were streaked on LB agar to obtain $24 \mathrm{~h}$ cultures to be used for all further studies. 


\subsubsection{Biofilm development}

Monospecific biofilm development was assessed at different times of exposure, using sterile 6 well plates (Nunc). Sterile coated and reference bare Ti discs were inoculated on their surface with $50 \mu \mathrm{L}$ bacterial suspension of $\sim 0.5$ McFarland density corresponding to $1-3^{*} 10^{7}$ density. The samples were allowed to incubate at $37^{\circ} \mathrm{C}$ in humid atmosphere and have been observed after three time periods ( $6 \mathrm{~h}, 24 \mathrm{~h}$ and $48 \mathrm{~h}$ ) to assess the temporal dynamics of developed biofilms. After incubation, the samples were carefully washed with sterile saline buffer to remove any unattached microbial cells and then immersed in $1 \mathrm{~mL}$ sterile saline buffer in Eppendorf tubes to reach biofilm detachment by vigorous vortexing. The resulting biofilm-detached cell suspensions were further serially ten-fold diluted and $10 \mu \mathrm{L}$ of each serial dilution were plated in triplicate on LB agar.

After $6 \mathrm{~h}, 24 \mathrm{~h}$ and $48 \mathrm{~h}$ of incubation at $37^{\circ} \mathrm{C}$, viable cell counts were performed and the number of colony forming units (CFU)/mL for each sample were estimated.

\section{Results and discussion}

\subsection{SEM, AFM, and EDS observations}

The optimal cellular response (cellular adhesion, spreading, and proliferation) is of great significance for tissue and medical engineering and is dependent on surface morphology and composition (Surmenev, 2012; Spencer, 2011).

The general surface morphology of the CHT-BmAp film has been first investigated by SEM. Fig. 2 displays the characteristic topological features of the C-MAPLE film in various surface regions of interest: far-most CHT rich region (S1), CHT-BmAp blended regions (with $\mathrm{CHT}$ decreasing from S2 to S4), and far-most BmAp rich region (S5).

SEM micrographs (Fig. 2) showed that the C-MAPLE blended coatings have a homogeneous spongy appearance all over the substrate, which is known to be beneficial for cell adhesion (Boyan et al., 1999; Chang and Wang, 2011; Willershausen et al., 2014; Zhu
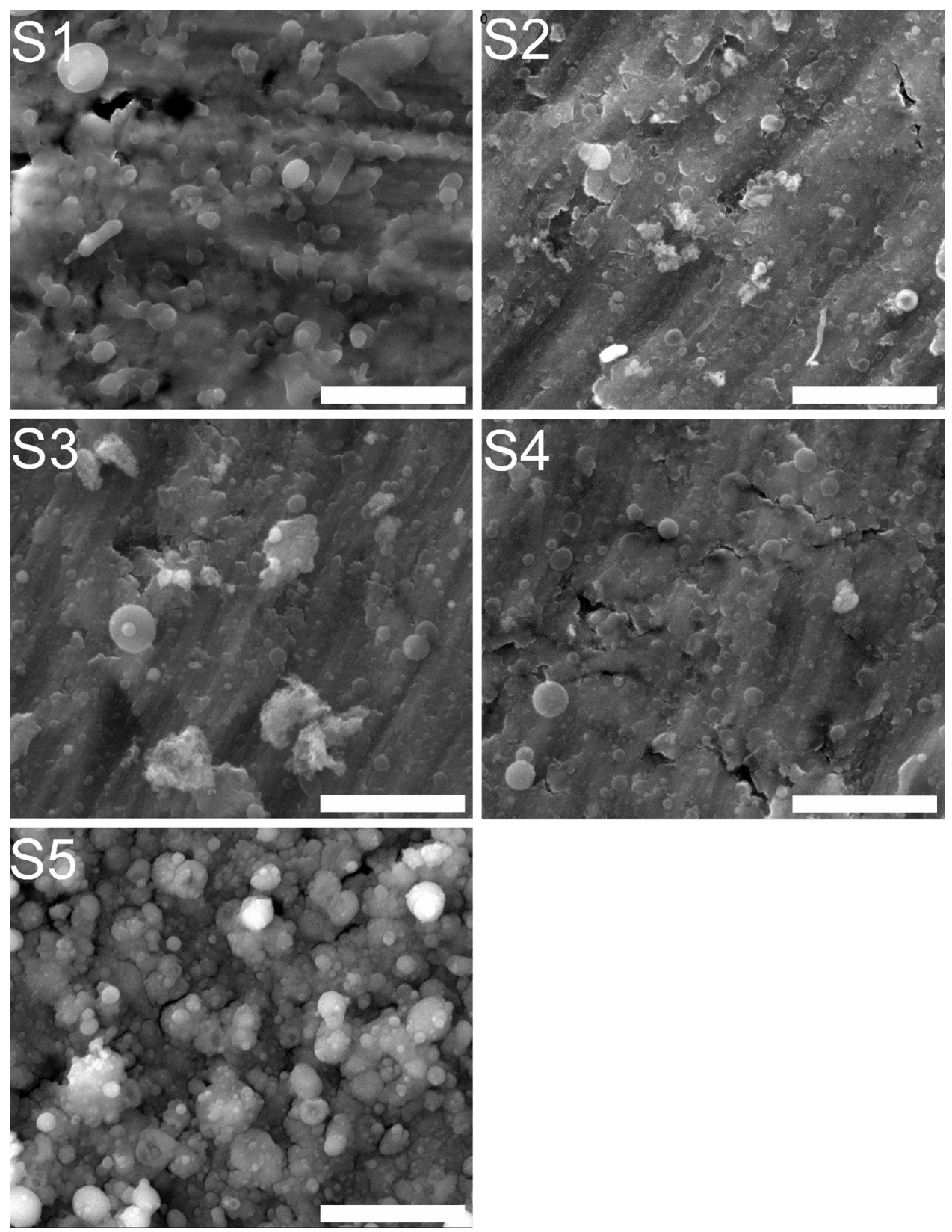

Fig. 2. SEM micrographs recorded in various regions of the CHT-BmAp coating obtained by C-MAPLE (magnification bar $=4 \mu \mathrm{m})$. 


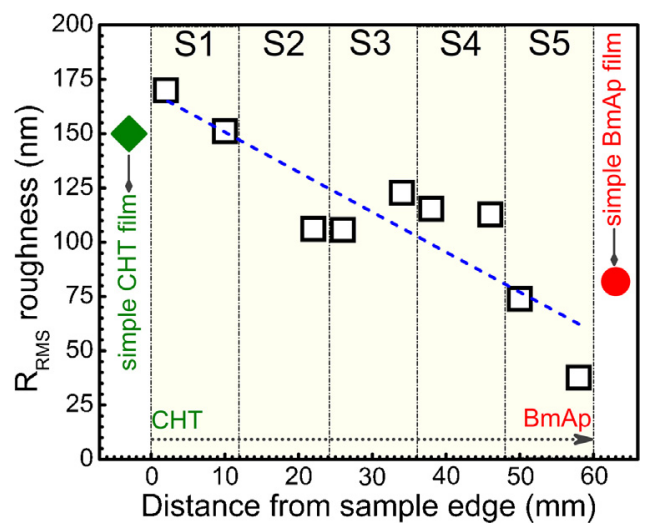

Fig. 3. Surface roughness $\left(\mathrm{R}_{\mathrm{RMS}}\right)$ evolution with the distance from the C-MAPLE film CHT-rich edge.

et al., 2015). Although, CHT particulates preserve their spherical morphology, while elongated filiform structures were also noticed in the blended regions of the film (i.e., S2-S4). It was stated that these threadlike structures could support some toughness improvements similar to the one provided by fibre reinforcing in the composite materials, ensuring the desired mechanical behavior for tissue substitution (Mikhailov et al., 2014).

Further, the roughness $\left(\mathrm{R}_{\mathrm{RMS}}\right)$ of the CHT-BmAp films have been inferred by AFM analyses. The evolution of the grains roughness along the substrate length is depicted in Fig. 3. One notices that a progressive increase of roughness ( $\mathrm{R}_{\mathrm{RMS}}$ ) occurs with the CHT concentration in the C-MAPLE composite films.

Fig. 4 presents characteristic EDS spectra collected from various regions of CHT-BmAp C-MAPLE blended film, starting with the CHT rich region. One can observe the progressive decrease of $\mathrm{C}-\mathrm{K} \alpha$ and $\mathrm{N}-\mathrm{K} \alpha$ lines with distance from the $\mathrm{CHT}$ rich edge, which is indicative of its gradual decrease of concentration in the sample. The $\mathrm{Ca} / \mathrm{P}$ molar ratio for each combinatorial surface was in the range $\sim 1.3-1.5$, thus lower than the stoichiometric theoretical value of hydroxyapatite (i.e., 1.67), pointing to the calciumdeficient state of biomimetic apatite synthesized.

\subsection{GIXRD investigation}

In the case of simple MAPLE films the only diffraction maxima (Fig. 5) pertain to the Ti substrate (ICDD: 00-044-1294) and to a titanium sub-oxide phase (TiO) (ICDD: 01-086-2352), visible due to the low thickness of the MAPLE films. The presence of TiO phase on the Ti surface might be the result of substrate manufacturing process. For BmAp film, a fairly pronounced hump has been observed in the $(25-35)^{\circ} 2 \theta$ range, where crystalline hydroxyapatite [HA, $\mathrm{Ca}_{10}\left(\mathrm{PO}_{4}\right)_{6}(\mathrm{OH})_{2}$ ] compounds exhibit their most intense lines. It is thus suggested that the BmAp MAPLE thin film is in amorphous state within the sensitivity limit of the employed XRD apparatus. No such halo has been revealed in the case of CHT MAPLE thin film. One may account this to the lower electron density of chitosan with respect to HA, determining a lower scattered intensity, hard to discriminate from the background noise.

\subsection{FTIR spectroscopy studies}

The FTIR spectra of BmAp, HA (pure and highly crystalline), and CHT powders are presented comparatively in Fig. 6a and b. One can notice the broader aspect of the IR bands in the case of BmAp powder with respect to the pure and highly crystalline HA material. Besides the characteristic (Markovic et al., 2004; Sima et al., 2010) $v_{4}$ bending, $v_{1}$ symmetric stretching and $v_{3}$ asymmetric stretching vibration bands of orthophosphate units of HA (Table 1 ), the BmAp powder elicited supplemental IR bands peaking at $\sim 872$, 1418,1480 and $1635 \mathrm{~cm}^{-1}$. The well-defined band at $\sim 872 \mathrm{~cm}^{-1}$ could be attributed to the superimposed contributions of the $v_{2}$ bending modes of carbonate groups and the vibrations exhibited by hydrogen phosphate ions $\left(\mathrm{HPO}_{4}\right)^{2-}$ (characteristic to nonapatitic domains). The weak band at $\sim 1635 \mathrm{~cm}^{-1}$ belongs to the bending mode of water molecules. It denotes the existence of hydration, and correlates well with the very broad band ranging from 3600 to $2500 \mathrm{~cm}^{-1}$, engendered by the stretching vibrations of adsorbed water molecules. The broad IR absorbance maxima of the BmAp powder spectrum, and the absence of the libration $\left(\sim 628 \mathrm{~cm}^{-1}\right)$ and stretching $\left(\sim 3571 \mathrm{~cm}^{-1}\right)$ modes of structural $(\mathrm{OH})^{-}$groups, point towards an apatite-like compound with a reduced degree of (short-range) order

The IR spectrum (Fig. 6a and b) of the CHT powder displays an intricate envelope with multiple vibration maxima. The two prominent bands, situated in the wave numbers regions (i) 3600$2500 \mathrm{~cm}^{-1}$ and (ii) $1100-950 \mathrm{~cm}^{-1}$, are ascribed to the (i) overlapped stretching vibrations of adsorbed water and $\mathrm{N}-\mathrm{H}$ bonds, and to the (ii) symmetric stretching vibrations of $\mathrm{C}-\mathrm{O}$ bonds in groups like $\mathrm{COH}, \mathrm{COC}$ and $\mathrm{CH}_{2} \mathrm{OH}$, respectively (Katti et al., 2008; Yuan et al., 2010; Paluszkiewicz et al., 2011; Silva et al., 2012). The low intensity, but sharp bands, centred at $($ iii $) \sim 1150 \mathrm{~cm}^{-1}$ and (iv) $\sim 890 \mathrm{~cm}^{-1}$, are related to the (iii) asymmetric stretching vibrations of $\mathrm{C}-\mathrm{O}$, and (iv) wagging vibrations of $\mathrm{C}-\mathrm{H}$ bonds of the saccharide groups of chitosan (Paluszkiewicz et al., 2011; Silva et al., 2012). The peaks at 1650,1591 and $1316 \mathrm{~cm}^{-1}$ are

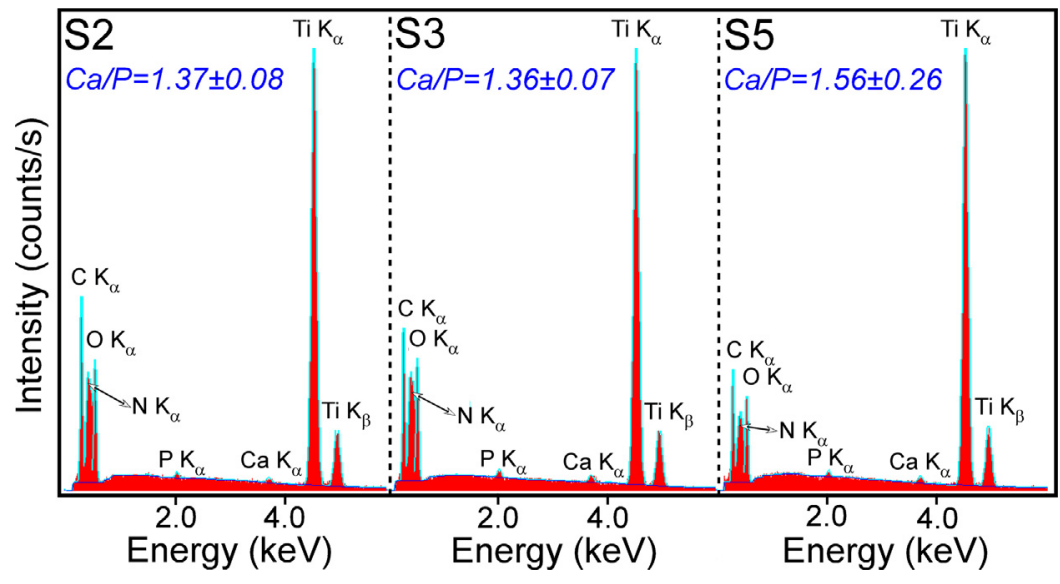

Fig. 4. EDS spectra collected in various regions of CHT-BmAp C-MAPLE blended film. 


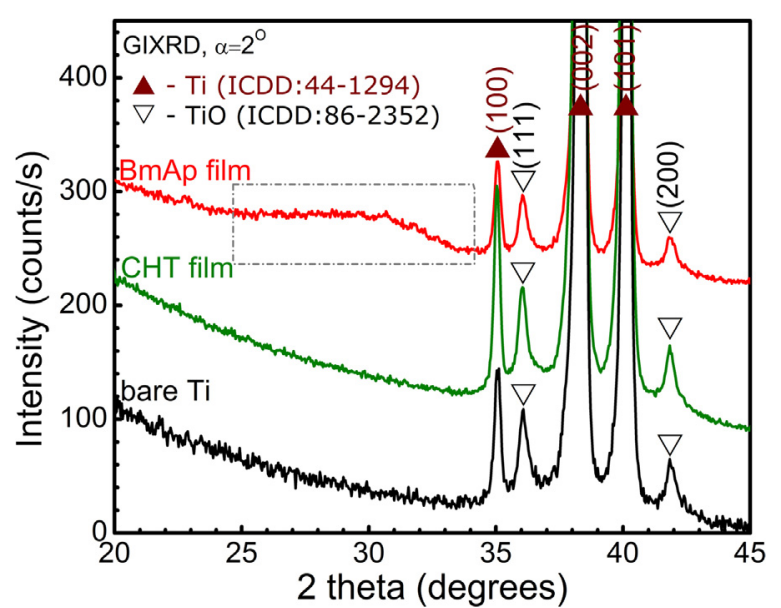

Fig. 5. Comparative GIXRD patterns of simple BmAp/Ti film, simple CHT/Ti film and bare Ti substrate.

characteristic to the vibrations of amides I, II and III groups, whilst the bands at 1420 and $1376 \mathrm{~cm}^{-1}$ are assigned to the symmetric deformation modes of $\mathrm{CH}_{3}$ (Katti et al., 2008; Yuan et al., 2010; Paluszkiewicz et al., 2011; Silva et al., 2012).

A complete assignment of the FTIR bands is presented in Table 1.

Fig. 6c and d display the comparative spectra recorded for the pure (CHT and BmAp) layers and blended (CHT-BmAp) thin film (in two regions situated close to CHT- and BmAp-rich edges of the film) deposited on titanium substrate. As a general observation, the spectra of pure CHT and BmAp layers elicit less defined IR envelopes with broader bands with respect to the parent powders, thus indicating a decreased structural order. This was to be expected for films synthesized at room temperature in nonequilibrium conditions by a physical vapor deposition method, such as MAPLE. However, remarkably, all major vibration bands of CHT and BmAP were detected in the case of films, furthermore having similar intensity ratio and featuring only slight wavelength shifts. The other minor vibration bands (observed more clearly in the case of powders) are assumed to be present, but overlapped to the broader, yet convoluted, major peaks. The conservation of similar levels of hydration (for both types of films) as the ones found in the parent materials can be also emphasized.

The blended CHT-BmAp film was analyzed in various regions situated on a median line, starting from the CHT-rich region, taking advantage of the ATR diamond head with a window area of $2.54 \mathrm{~mm}^{2}$. In this way the compositional evolution of the blended film was unveiled (Fig. $7 \mathrm{a}$ and b). One can notice that even in the regions situated in the BmAp-richer edge of the film, the CHT bands are dominant (Figs. 6 and 7). This suggests that the CHT plume was superior expanded, whilst the BmAp was better confined, due to their different ablation and/or volatilization rates. However, the (large) shifts to intermediate positions and the shape of the peaks situated in the $1200-800 \mathrm{~cm}^{-1}$ region are suggesting that an interaction of CHT molecules with BmAp is
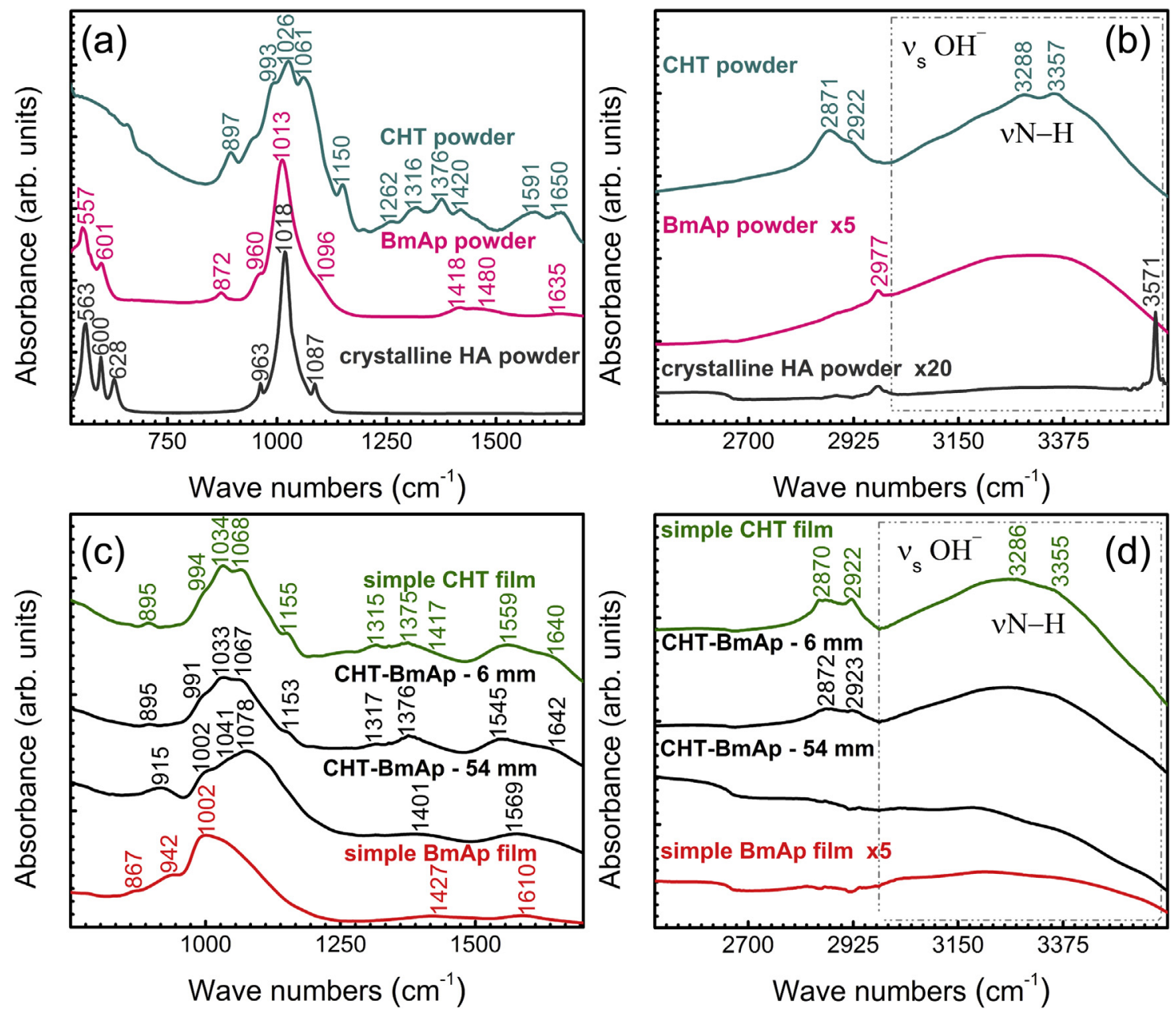

Fig. 6. Comparative FTIR spectra of CHT, BmAp, and crystalline HA powders (a,b), and simple CHT, BmAp, and CHT-BmAp films (c,d) in the fingerprint (a,c) and functional groups (b,d) regions. For a better visual evaluation, the spectra were normalized to the intensity of the most prominent band centred at $\sim 1040-1010 \mathrm{~cm}^{-1}$. 

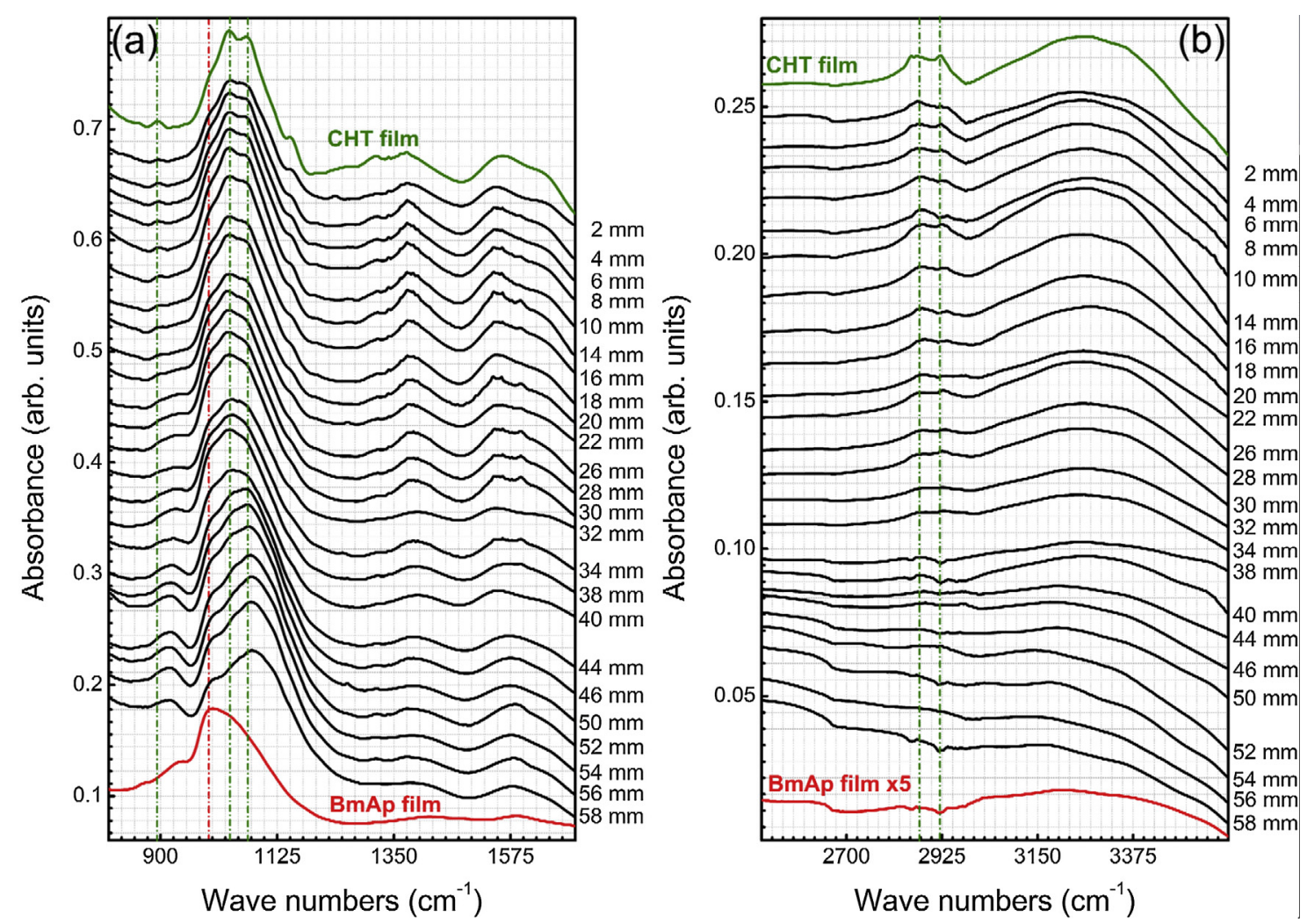

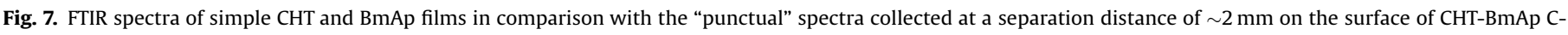

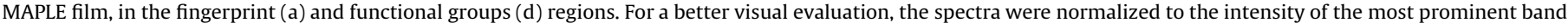
centred at $\sim 1040-1010 \mathrm{~cm}^{-1}$.

occurring. As expected, with the increase of the distance from the BmAp-richer edge of the film, the BmAp vibration bands start fading, whilst the CHT bands become more and more pronounced, and are progressively shifted to the positions recorded in the case of the pure CHT film (Fig. 7a and b). Concomitantly, one can observe a continuous change of the vibration bands shape, which evolves from a CHT-BmAp intermingled spectrum to an IR envelope allure closely resembling the one of pure CHT (Fig. 7a and $b$ ).

\subsection{Micro-Raman spectroscopy investigations}

Similar vibration bands to the ones revealed by FTIR investigations (Fig. 7a and $\mathrm{b}$ and Table 1 ) have been also identified by micro-Raman analyses for the CHT and BmAp source materials. (results not shown here). However, in the case of Raman spectra the symmetric stretching bands are the dominant ones.

In perfect agreement with the FTIR results, the Raman spectra evidenced that the BmAp material elicit along combinatorial trajectory a decreased ordering (indicated by the broader aspect of the bands) and a certain level hydration with respect to the pure and crystalline HA.

\subsection{XPS analysis}

XPS analysis confirmed the chemical composition of the CHTBmAp C-MAPLE composite films. XPS survey spectra collected on the surface of CHT-BmAp samples (not presented) indicated the presence of $\mathrm{C} 1 \mathrm{~s}, \mathrm{O} 1 \mathrm{~s}, \mathrm{~N} 1 \mathrm{~s}, \mathrm{Ca} 2 \mathrm{~s}, \mathrm{Ca} 2 \mathrm{p}, \mathrm{P} 2 \mathrm{~s}$ and $\mathrm{P} 2 \mathrm{p}$ photoelectron peaks.

Fig. 8 shows the atomic ratio $\mathrm{N} 1 \mathrm{~s} /(\mathrm{N} 1 \mathrm{~s}+\mathrm{Ca} 2 \mathrm{p})$ evolution depending on the position along the CHT-BmAp blended sample. As predicted, the atomic ratio $(\mathrm{N} 1 \mathrm{~s} / \mathrm{N} 1 \mathrm{~s}+\mathrm{Ca} 2 \mathrm{p})$ is decreasing from
CHT to BmAp compounds, evidencing the composition gradient of the combinatorial films.

\subsection{Antimicrobial activity assay}

Composite biomaterials comprising Ap and polymers have shown promising features for bone tissue engineering. Previous studies have proven the high antimicrobial activity of CHT/Ap composite particles (Ignjatović et al., 2016; Shi et al., 2016). However, the most of the chitosan containing coatings reported in the literature have been obtained by using electrophoretic deposition or hydrothermal fabrication methods (Seuss et al., 2014; Pishbin et al., 2014; Long et al., 2014).

During this studies, the antibiofilm properties of the C-MAPLE deposited coatings containing $\mathrm{CHT}$ and $\mathrm{BmAp}$ in various ratios have been tested using two microbial strains, which are representative for the Gram positive ( $S$. aureus) and Gram negative (E. coli) bacterial infections. Such pathogens could contaminate the orthopedic implants by route of exogenous or endogenous infections, leading to the occurrence of implant-associated infections, which are hard to treat and could often lead to implant failure. S. aureus, together with S. epidermidis accounts for $30 \%$ to two thirds of all implant-related infections, while among Gramnegative bacteria, the etiology is dominated by E. coli (Sendi et al., 2011; Campoccia et al., 2006; Esposito and Leone, 2008). However, little is known about the virulence features of $E$. coli strains involved in prosthetic infections. A recent study has revealed that no specific pathogenic signature or increased ability to form biofilms in vitro were detected in E. coli strains isolated from orthopedic infections, as compared to fecal isolates (Crémet et al., 2012).

The biofilm formation is a multi-stage process starting with the initial attachment of bacterial cells, followed by cell aggregation 
Table 1

The assignment of FTIR bands of chitosan and hydroxyapatite.

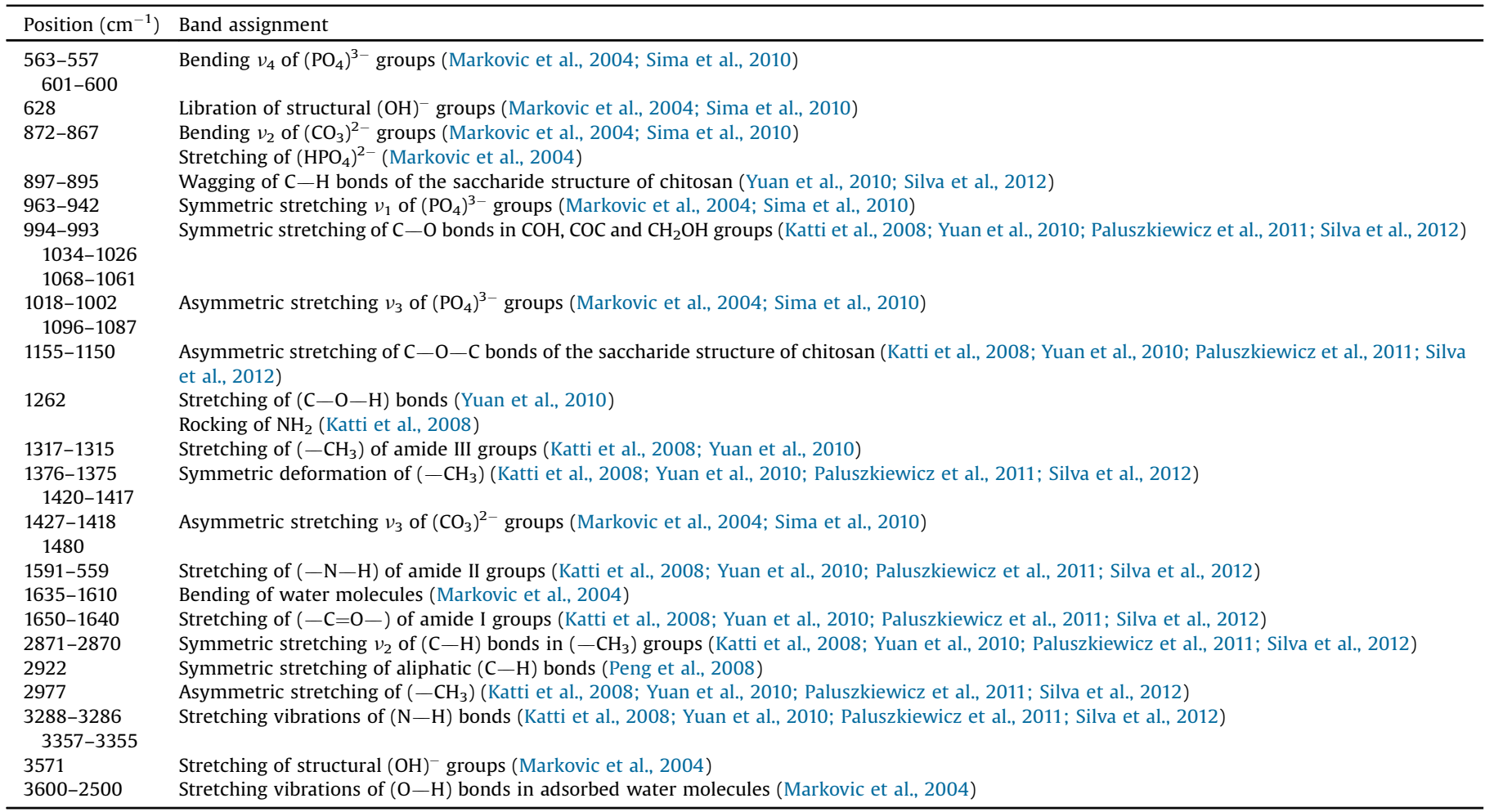

and accumulation in multiple cell layers, biofilm maturation and biofilm cells detachment (Arciola et al., 2015). In our study, the development of biofilms consisting of the Gram-positive $S$. aureus and the Gram-negative E. coli followed a different dynamic on the tested samples. Thus, both $S$. aureus and $E$. coli biofilms grown on the control (bare Ti substrate) revealed a similar dynamic, i.e., a decreasing trend of biofilm embedded viable cells, quantified at the three consecutive point intervals (Fig. 9). These results are suggesting that the high surface roughness of bare Ti substrate required for an improved osseointegration favors the rapid and firm adhesion of $S$. aureus and $E$. coli cells. This behavior supports the leading position held by these species in the etiology of implant-associated infections.

Fig. 9 In the case of microbial biofilms development on the CHTBmAp surfaces, a more pronounced inhibitory effect was generally

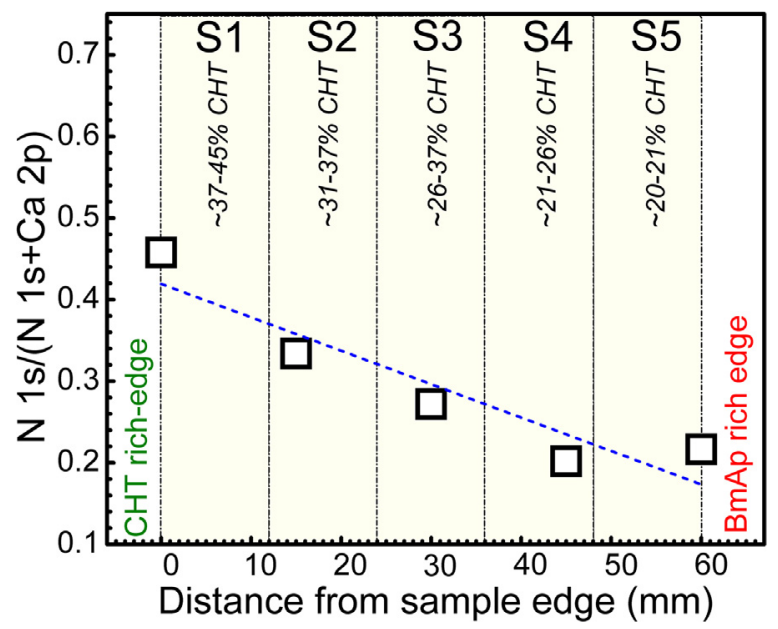

Fig. 8. Typical XPS measurement along the composite CHT-BmAp C-MAPLE films. observed against the Gram-positive $S$. aureus biofilm, as compared to E. coli, for all the three tested time intervals (Fig. 10). The S2, S3 and S4 samples inhibited the first stage of S. aureus initial microbial adherence to the tested surface quantified after $6 \mathrm{~h}$, while none of the tested samples inhibited the adherence of the Gram-negative $E$. coli strain (Fig. 10a). At $24 \mathrm{~h}$, all tested CHT-BmAp samples decreased the number of $S$. aureus biofilm embedded cells (Fig. 10b); the most intensive inhibitory effect being observed

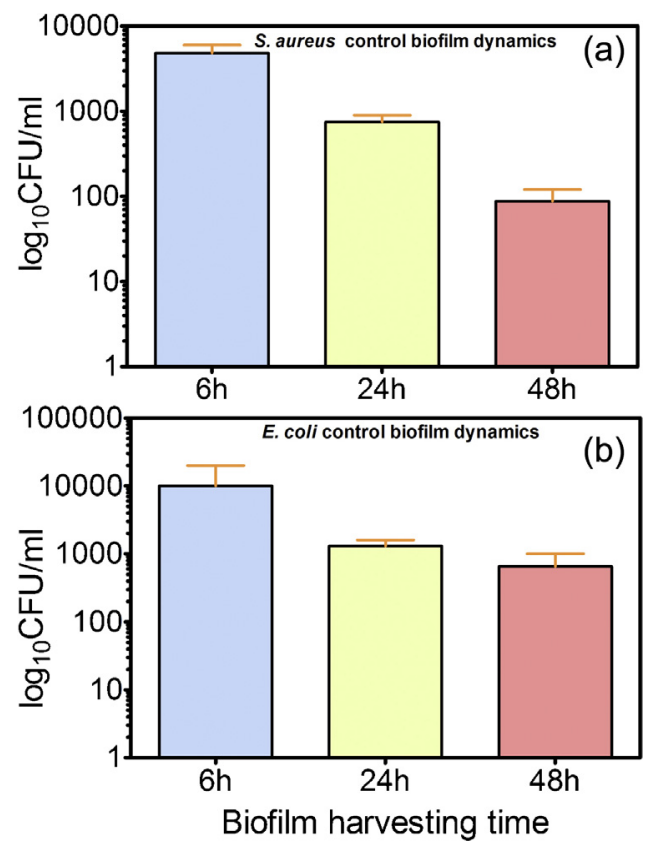

Fig. 9. Graphic representation of the number of viable biofilm embedded (a) $S$. aureus and (b) E. coli cells developed on the bare Ti substrate used as control. 

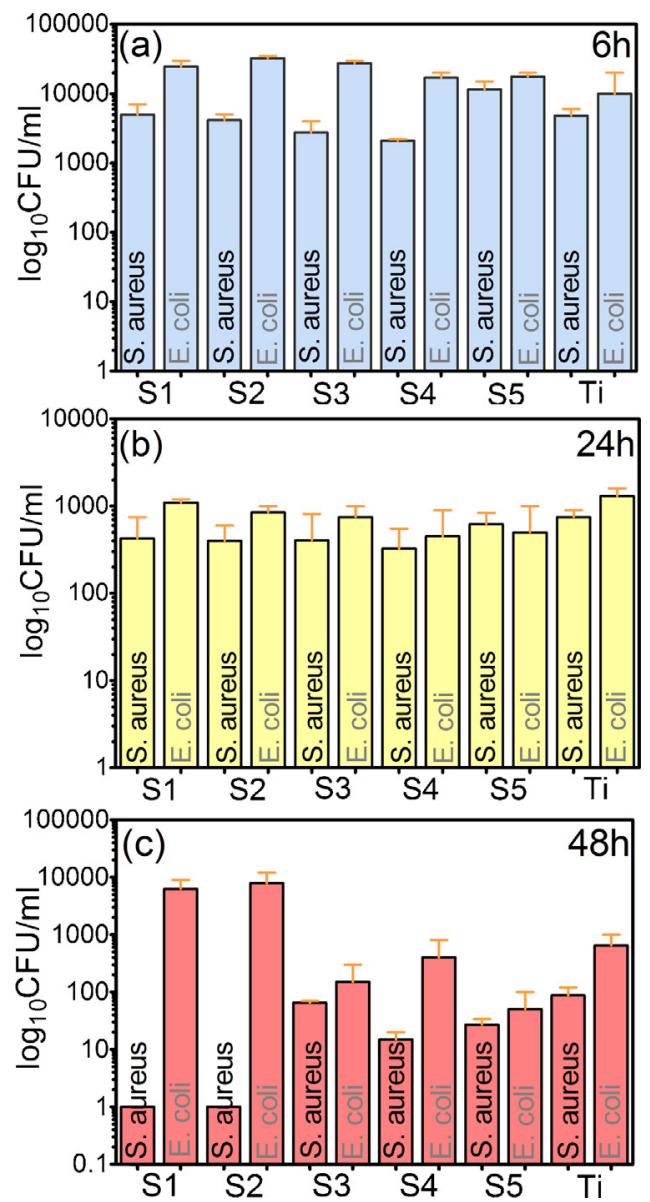

Fig. 10. Graphic representation of the number of viable microbial cells adhered to the surface of CHT-BmAp composite film after (a) $6 \mathrm{~h}$, (b) $24 \mathrm{~h}$ and (c) $48 \mathrm{~h}$ of incubation.

for the S4 sample in the case of S. aureus biofilm. The E. coli biofilm development was inhibited by the S1-S5 samples, but the most intensive antibiofilm effect was noticed for S4 and S5 (Fig. 10b).

An intensive anti-biofilm effect was exhibited after $48 \mathrm{~h}$ against S. aureus in the case of all CHT-BmAp tested samples (Fig. 10c) but the most significant activity was observed for S1 and S2 samples. The $E$. coli biofilm was inhibited only by $\mathrm{S} 3-\mathrm{S} 5$ samples, the most intensive effect being noticed for S5 (Fig. 10c).

Taken together, the results regarding the anti-biofilm effect of the obtained coatings exhibited against both biofilm types and for the three tested intervals recommend S3 and S4 as the most promising compositions, assuring an anti-biofilm protection on a long period of time against both bacterial species (Table 2).

Although the mechanisms of antimicrobial action of CHT are not elucidated, the literature states that its target is at the microbial cell surface, as suggested by the electron microscopy findings. They show cellular wall disorganization both in Gram-positive and Gram-negative bacteria, as well as in fungal strains, due to the electrostatic interaction of positively-charged-CHT with the negatively charged bacterial components (proteins, phospholipids) (Cuero, 1999; Muzzarelli et al., 1990; No et al., 2002). This action mechanism is responsible for a wide spectrum of the antimicrobial activity of CHT and its derivatives including filamentous fungi, yeasts and bacteria (Raafat and Sahl, 2009). Nevertheless, it seems that CHT is more active against Grampositive than Gram-negative bacteria, as revealed also by our study. In this regard, $S$. aureus biofilm proved to be more susceptible than $E$. coli, probably due to the stronger interaction
Table 2

Synthetic representation of the anti-biofilm efficiency of the CHT-BmAp surfaces depending on the biofilm species and development stage.

\begin{tabular}{|c|c|c|c|c|c|c|}
\hline \multirow{2}{*}{$\frac{\text { Species }}{\text { Incubation time }}$} & \multicolumn{3}{|c|}{ S. aureus } & \multicolumn{3}{|c|}{ E. coli } \\
\hline & $6 h$ & $24 \mathrm{~h}$ & $48 \mathrm{~h}$ & $6 h$ & $24 \mathrm{~h}$ & $48 \mathrm{~h}$ \\
\hline S1 & & $\mathrm{x}$ & $\mathrm{x}$ & & $x$ & \\
\hline S2 & $\mathrm{x}$ & $\mathrm{x}$ & $\mathrm{x}$ & & $\mathrm{x}$ & \\
\hline S3 & $\mathbf{x}$ & $\mathbf{x}$ & $\mathbf{x}$ & & $\mathbf{x}$ & $\mathbf{x}$ \\
\hline S4 & $\mathbf{x}$ & $\mathbf{x}$ & $\mathbf{x}$ & & $\mathbf{x}$ & $\mathbf{x}$ \\
\hline S5 & & $\mathrm{x}$ & $\mathrm{x}$ & & $\mathrm{x}$ & $\mathrm{x}$ \\
\hline
\end{tabular}

of CHT with the amino acids rich fraction of the Gram-positive bacterial wall (Kumar et al., 2005). In exchange, the Gram-negative strains have a more complex cellular wall due to the negativelycharged lipopolysaccharides which can act as an additional barrier in the interaction of chitosan with other structures of the cellular wall and membrane (Helander et al., 2001).

\section{Conclusions}

The synthesized CHT-BmAp blended thin films are amorphous, rough, with a morphology characteristic to MAPLE structures. The composition gradient of the chitosan-to-biomimetic hydroxyapatite has been confirmed longwise the combinatorial films.

The antimicrobial activity was controlled by the concentration of chitosan, while the blended structures were better integrated for quasi-equal presence of the two compounds (i.e., chitosan and biomimetic apatite). The most efficient antimicrobial activity, considered as long-term protection against initial adhesion and biofilms developed by Gram-positive and Gram-negative strains, was assigned to S3 and S4 samples.

C-MAPLE technique used in this study proves to be a prospective and viable method for the fabrication of biomimetic and bioactive antimicrobial orthopedic coatings which resemble the native bone extracellular matrix (consisting of water, minerals, fibrous proteins, proteoglycans) and thus, create a favorable living environment for osteogenic cells, while assuring protection from microbial colonization.

\section{Acknowledgements}

The authors acknowledge the financial support of UEFISCDI under the France-Romania bilateral contract 778/2014, the "Ministère des Affaires étrangères" under the PHC BRANCUSI 2015 ( $\mathrm{N}^{\circ}$ 32648SD) and the National Authority for Scientific Research and Innovation in the frame of Nucleus Programme contract $4 \mathrm{~N} / 2016$. The authors thank to Iuliana Urzica for performing the profilometry thickness measurements. G.E.S. acknowledges with thanks the support of NIMP Core Programme PN 16 48-3/2016. The authors acknowledge with thanks the help of Dr. Felix Sima and Dr. Emanuel Axente for assistance for the design and set-up of the C-MAPLE experiment.

\section{References}

Agarwal, R. García, A.J. 2015. Biomaterial strategies for engineering implants for enhanced osseointegration and bone repair. Adv. Drug Deliv. Rev. 94, 53-62.

Arciola, C.R., Campoccia, D., Ehrlich, G.D., Montanaro, L., 2015. Biofilm-based implant infections in orthopaedics. Adv. Exp. Med. Biol. 830, 29-46.

Axente, E. Sima, F. Sima, L.E., Erginer, M., Eroglu, M.S., Serban, N., Ristoscu, C., Petrescu, S.M., Stefana, Toksoy Oner, E., Mihailescu, I.N., 2014. Combinatorial MAPLE gradient thin film assemblies signalling to human osteoblasts. Biofabrication 6, 035010.

Blind, O., Klein, L.H., Dailey, B., Jordan, L., 2005. Characterization of hydroxyapatite films obtained by pulsed-laser deposition on Ti and Ti-6AL-4 v substrates. Dent. Mater. 21, 1017-1024.

Boyan, B.D., Lincks, J., Lohmann, C.H., Sylvia, V.L., Cochran, D.L., Blanchard, C.R. Dean, D.D., Schwartz, Z., 1999. Effect of surface roughness and composition on 
costochondral chondrocytes is dependent on cell maturation state. J. Orthop. Res. 17, 446-457.

Campoccia, D., Montanaro, L., Arciola, C.R., 2006. The significance of infection related to orthopedic devices and issues of antibiotic resistance. Biomaterials 27, 2331-2339.

Chang, H.I., Wang, Y., 2011. Cell responses to surface and architecture of tissue engineering scaffolds. In: Eberli, D. (Ed.), Regenerative Medicine and Tissue Engineering-Cells and Biomaterials. InTech, Rijeka, pp. 569-588.

Chifiriuc, M.C., Grumezescu, A.M., Grumezescu, V., Bezirtzoglou, E., Lazar, V., Bolocan, A., 2014. Biomedical applications of natural polymers for drug delivery. Curr. Org. Chem. 18, 152-164.

Crémet, L., Corvec, S., Bémer, P., Bret, L., Lebrun, C., Lesimple, B., Miegeville, A.F., Reynaud, A., Lepelletier, D., Caroff, N., 2012. Orthopaedic-implant infections by Escherichia coli: molecular and phenotypic analysis of the causative strain. J. Infect. 64, 169-175.

Cristescu, R., Popescu, C., Popescu, A.C., Popescu, C., Socol, G., Mihailescu, I.N., Caraene, G., Albulescu, R., Buruiana, T., Chrisey, D., 2012. Pulsed laser processing of functionalized polysaccharides for controlled release drug delivery systems: functionalized polysaccharides processed for drug delivery. NATO Science for Peace and Security Series A: Chemistry and Biology. Springer, pp. 231-236.

Cuero, R.G., 1999. Antimicrobial action of exogenous chitosan. In: Jollès, P., Muzzarelli, R.A.A. (Eds.), Chitin and Chitinases. Birkhäuser Verlag, Basel, pp. 315-333.

Dai, T., Tanaka, M., Huang, Y.Y., Hamblin, M.R., 2011. Chitosan preparations for wounds and burns: antimicrobial and wound-healing effects. Expert Rev. Anti Infect. Ther. 9, 857-879.

Davidenko, N., Carrodeguas, R.G., Peniche, C., Solís, Y., Cameron, R.E., 2010. Chitosan/ apatite composite beads prepared by in situ generation of apatite or Si-apatite nanocrystals. Acta Biomater. 6, 466-476.

Derakhshandeh, K., Fathi, S., 2012. Role of chitosan nanoparticles in the oral absorption of Gemcitabine. Int. J. Pharm. 437, 172-177.

Dorozhkin, S.V., 2009. Nanodimensional and nanocrystalline apatites and other calcium orthophosphates in biomedical engineering, biology and medicine. Materials 2, 1975-2045.

Duta, L., Oktar, F.N., Stan, G.E., Popescu-Pelin, G., Serban, N., Luculescu, C., Mihailescu, I.N., 2013. Novel doped hydroxyapatite thin films obtained by pulsed laser deposition. Appl. Surf. Sci. 265, 41-49.

Dutta, P.K., Tripathi, S., Mehrotra, G.K., Dutta, J., 2009. Perspectives for chitosan based antimicrobial films in food applications. Food Chem. 114, 1173-1182.

Eason, R., 2006. Pulsed Laser Deposition of Thin Films: Applications-Led Growth of Functional Materials. John Wiley \& Sons, Hoboken (NJ).

Eichert, D., Drouet, C., Sfihi, H., Rey, C., Combes, C., 2007. Nanocrystalline apatite based biomaterials: synthesis, processing and characterization. In: Kendall, J.B. (Ed.), Biomaterials Research Advances. Nova Science Publishers, New York, pp. 93-143.

Esposito, S., Leone, S., 2008. Prosthetic joint infections: microbiology, diagnosis, management and prevention. Int. J. Antimicrob. Agents 32, 287-293.

Gan, Q., Wang, T., 2007. Chitosan nanoparticle as protein delivery carriersystematic examination of fabrication conditions for efficient loading and release. Colloids Surf. B 59, 24-34.

Grossin, D., Rollin-Martinet, S., Estournes, C., Rossignol, F., Champion, E., Combes, C., Rey, C., Geoffroy, C. Drouet, C., 2010. Biomimetic apatite sintered at very low temperature by spark plasma sintering: physico-chemistry and microstructure aspects. Acta Biomater. 6, 577-585.

Grumezescu, A.M., Saviuc, C., Holban, A., Hristu, R., Croitoru, C., Stanciu, G., Chifiriuc, C., Mihaiescu, D., Balaure, P., Lazar, V., 2011. Magnetic chitosan for drug targeting and in vitro drug delivery response. Biointerf. Res. Appl. Chem. 1, 160-165.

Grumezescu, A.M., Andronescu, E., Ficai, A., Bleotu, C., Mihaiescu, D.E., Chifiriuc, M. C., 2012. Synthesis, characterization and in vitro assessment of the magnetic chitosan-carboxymethylcellulose biocomposite interactions with the prokaryotic and eukaryotic cells. Int. J. Pharm. 436, 771-777.

Helander, I.M., Nurmiaho-Lassila, E.L., Ahvenainen, R., Rhoades, J., Roller, S., 2001. Chitosan disrupts the barrier properties of the outer membrane of Gramnegative bacteria. Int. J. Food Microbiol. 71, 235-244.

Hu, Q., Li, B., Wang, M., Shen, J., 2004. Preparation and characterization of biodegradable chitosan/hydroxyapatite nanocomposite rods via in situ hybridization: a potential material as internal fixation of bone fracture. Biomaterials 25, 779-785.

Ignjatović, N., Wu, V., Ajduković, Z., Mihajilov-Krstev, T., Uskoković, V., Uskoković, D., 2016. Chitosan-PLGA polymer blends as coatings for hydroxyapatite nanoparticles and their effect on antimicrobial properties, osteoconductivity and regeneration of osseous tissues. Mater. Sci. Eng. C 60, 357-364.

Ito, M., Hidaka, Y., Nakajima, M., Yagasaki, H., Kafrawy, A.H., 1999. Effect of hydroxyapatite content on a physical properties and connective tissue reactions to a chitosan-hydroxyapatite composite membrane. J. Biomed. Mater. Res. 45, 204-208.

Jia, L.N., Liang, C.H., Huang, N.B., Zhou, Z.M., Duan, F., Wang, L.X., 2016a. Morphology and composition of coatings based on hydroxyapatite-chitosan-RuCl3 system on AZ91D prepared by pulsed electrochemical deposition. J. Alloy. Compd. 656, 961-971.

Jia, Z., Xiu, P., Li, M., Xu, X., Shi, Y., Cheng, Y., Wei, S., Zheng, Y., Xi, T., Cai, H., Liu, Z., 2016b. Bioinspired anchoring AgNPs onto micro-nanoporous $\mathrm{TiO}_{2}$ orthopedic coatings: trap-killing of bacteria, surface-regulated osteoblast functions and host responses. Biomaterials 75, 203-222.
Katti, K.S., Katti, D.R., Dash, R., 2008. Synthesis and characterization of a novel chitosan/montmorillonite/hydroxyapatite nanocomposite for bone tissue engineering. Biomed. Mater. 3, 034122.

Kim, S., Kim, J.H., Jeon, O., Kwon, I.C., Park, K., 2008. Engineered polymers for advanced drug delivery. Eur. J. Pharm. Biopharm. 71, 420-430.

Kong, M., Chen, X.G., Xing, K., Park, H.J., 2010. Antimicrobial properties of chitosan and mode of action: a state of the art review. Int. J. Food Microbiol. 144, 51-63.

Kumar, A.B.V., Varadaraj, M.C., Gowda, L.R., Tharanathan, R.N., 2005. Characterization of chito-oligosaccharides prepared by chitosanolysis with the aid of papain and pronase, and their bactericidal action against Bacillus cereus and Escherichia coli. Biochem. J. 391, 167-175.

Leceta, I., Guerrero, P., Ibarburu, I., Dueñas, M.T., de la Caba, K., 2013. Characterization and antimicrobial analysis of chitosan-based films. J. Food Eng. 116, 889-899.

Lee, M., Li, W., Siu, R.K., Whang, J., Zhang, X., Soo, C., Ting, K., Wu, B.M., 2009. Biomimetic apatite-coated alginate/chitosan microparticles as osteogenic protein carriers. Biomaterials 30, 6094-6101.

Li, X., Nan, K., Shi, S., 2012. H. Chen Preparation and characterization of nanohydroxyapatite/chitosan cross-linking composite membrane intended for tissue engineering. Int. J. Biol. Macromol. 50, 43-49.

Li, X., Ma, X.Y., Feng, Y.F., Ma, Z.S., Wang, J., Ma, T.C., Qi, W., Lei, W., Wang, L., 2015. Osseointegration of chitosan coated porous titanium alloy implant by reactive oxygen species-mediated activation of the PI3 K/AKT pathway under diabetic conditions. Biomaterials 36, 44-54.

Long, T., Liu, Y.T., Tang, S., Sun, J.L., Guo, Y.P., Zhu, Z.A., 2014. Hydrothermal fabrication of hydroxyapatite/chitosan/carbon porous scaffolds for bone tissue engineering. J. Biomed. Mater. Res. B Appl. Biomater. 102, 1740-1748.

Ma, X.Y., Feng, Y.F., Ma, Z.S., Li, X., Wang, J., Wang, L., Lei, W., 2014. The promotion of osteointegration under diabetic conditions using chitosan/hydroxyapatite composite coating on porous titanium surfaces. Biomaterials 35, 7259-7270.

Markovic, M., Fowler, B.O., Tung, M.S., 2004. Preparation and comprehensive characterization of a calcium hydroxyapatite reference material. J. Res. Natl. Inst. Stand. Technol. 109, 553-568.

Martins, A.F., Facchi, S.P., Follmann, H.D.M., Pereira, A.G.B., Rubira, A.F., Muniz, E.C. 2014. Antimicrobial activity of chitosan derivatives containing $\mathrm{N}$-quaternized moieties in its backbone: a review. Int. J. Mol. Sci. 15, 20800-20832.

Meredith, J.C., Karim, A., Amis, E.J., 2000. High-throughput measurement of polymer blend phase behavior. Macromolecules 33, 5760-5762.

Mihailescu, N., Stan, G.E., Duta, L., Chifiriuc, M.C., Bleotu, C., Sopronyi, M., Luculescu, C., Oktar, F.N., 2016. I.N. Mihailescu Structural, compositional, mechanical characterization and biological assessment of bovine-derived hydroxyapatite coatings reinforced with $\mathrm{MgF}_{2}$ or $\mathrm{MgO}$ for implants functionalization. Mater. Sci. Eng. C 59, 863-874.

Mikhailov, G.P., Tuchkov, S.V., Lazarev, V.V., Kulish, E.I., 2014. Complexation of chitosan with acetic acid according to Fourier Transform Raman Spectroscopy data. Russ. J. Phys. Chem. A 88, 973-978.

Muzzarelli, R., Tarsi, R., Filippini, O., Giovanetti, E., Biagini, G., Varaldo, P.E., 1990. Antimicrobial properties of N-carboxybutyl chitosan. Antimicrob. Agents Chemother. 34, 2019-2023.

Nair, L.S., Laurencin, C.T., 2006. Polymers as biomaterials for tissue engineering and controlled drug delivery. Adv. Biochem. Eng. Biotechnol. 102, 47-90.

No, H.K., Park, N.Y. Lee, S.H., Meyers, S.P., 2002. Antibacterial activity of chitosans and chitosan oligomers with different molecular weights. Int. J. Food Microbiol. $74,65-72$.

Noel, P., Courtney, H., Bumgardner, J.D., Haggard, W.O., 2008. Chitosan films: a potential local drug delivery system for antibiotics. Clin. Orthop. Relat. Res. 466 1377-1382.

Paluszkiewicz, E., Stodolak, M., Hasik, M., 2011. FT-IR study of montmorillonitechitosan nanocomposite materials. Spectrochim. Acta A 79, 784-788.

Peña, J., Izquierdo-Barba, I., García, M.A., Vallet-Regí, M., 2006. Room temperature synthesis of chitosan/apatite powders and coatings. J. Eur. Ceram. Soc. 26, 3631-3638.

Peng, P., Wark, I., Voelcker, N.H., Kumar, S., Griesser, H.J., 2008. Concurrent elution of calcium phosphate and macromolecules from alginate/chitosan hydrogel coatings. Biointerphases 3, 105-116.

Pishbin, F., Mouriño, V., Flor, S., Kreppel, S., Salih, V., Ryan, M.P., Boccaccini, A.R. 2014. Electrophoretic deposition of gentamicin-loaded bioactive glass/chitosan composite coatings for orthopaedic implants. ACS Appl. Mater. Interfaces 6, 8796-8806.

Raafat, D., Sahl, H., 2009. Chitosan and its antimicrobial potential - a critical literature survey. Microb. Biotechnol. 2, 186-201.

Sendi, P., Banderet, F., Graber, P., Zimmerli, W., 2011. Periprosthetic joint infection following Staphylococcus aureus bacteremia. J. Infect. 63, 17-22.

Seuss, S., Lehmann, M., Boccaccini, A.R., 2014. Alternating current electrophoretic deposition of antibacterial bioactive glass-chitosan composite coatings. Int. J. Mol. Sci. 15, 2231-2242.

Shi, Y.Y., Li, M., Liu, Q., Jia, Z.J., Xu, X.C., Cheng, Y., Zheng, Y.F., 2016. Electrophoretic deposition of graphene oxide reinforced chitosan-hydroxyapatite nanocomposite coatings on Ti substrate. J. Mater. Sci.-Mater. Med. 27, 48.

Silva, C.R.C., Braga, M.V.L., Fook, C.M.O., Raposo, L.H., Carvalho, E.L., 2012. Application of infrared spectroscopy to analysis of chitosan/clay nanocomposites. In: Theophile, T. (Ed.), Infrared Spectroscopy - Materials Science, Engineering and Technology. InTech, Rijeka, pp. 43-62.

Sima, F., Mihailescu, I.N., 2013. Biomimetic assemblies by matrix-Assisted pulsed laser evaporation. In: Schmidt, V., Belegratis, M.R. (Eds.), Laser Technology in 
Biomimetics, Part of Series: Biological and Medical Physics, Biomedical Engineering. Springer-Verlag, Heidelberg, New York, pp. 111-141.

Sima, L.E., Stan, G.E., Morosanu, C.O., Melinescu, A., Ianculescu, A., Melinte, R., Neamtu, J., Petrescu, S.M., 2010. Differentiation of mesenchymal stem cells onto highly adherent radio frequency-sputtered carbonated hydroxylapatite thin films. J. Biomed. Mater. Res. A 95A, 1203-1214.

Sima, F., Axente, E., Sima, L.E., Tuyel, U., Eroglu, M.S., Serban, N., Ristoscu, C., Petrescu, S.M., Toksoy Oner, E., Mihailescu, I.N., 2012. Combinatorial MatrixAssisted Pulsed Laser Evaporation: single-step synthesis of biopolymer compositional gradient thin film assemblies. Appl. Phys. Lett. 101, 233705.

Sima, F., Axente, E., Iordache, I., Luculescu, C., Gallet, O., Anselme, K., Mihailescu, I.N. 2014. Combinatorial Matrix Assisted Pulsed Laser Evaporation of a biodegradable polymer and fibronectin for protein immobilization and controlled release. Appl. Surf. Sci. 306, 75-79.

Simchi, A., Tamjid, E., Pishbin, F., Boccaccini, A.R., 2011. Recent progress in inorganic and composite coatings with bactericidal capability for orthopaedic applications. Nanomed.-Nanotechnol. Biol. Med. 7, 22-39.

Sivakumar, M., Manjubala, I., Panduranga Rao, K., 2002. Preparation, characterization and in-vitro release of gentamicin from coralline hydroxyapatite-chitosan composite microspheres. Carbohydr. Polym. 49, 281288.

Sogias, I.A., Williams, A.C., Khutoryanskiy, V.V., 2012. Chitosan-based mucoadhesive tablets for oral delivery of ibuprofen. Int. J. Pharm. 436, 602-610.

Song, L., Gan, L., Xiao, Y.F., Wu, Y., Wu, F., Gu, Z.W., 2011. Antibacterial hydroxyapatite/chitosan complex coatings with superior osteoblastic cell response. Mater. Lett. 65, 974-977.

Spencer, N.D., 2011. Tailoring Surfaces: Modifying Surface Composition and Structure for Applications in Tribology, Biology and Catalysis. World Scientific Publishing Company, London.

Surmenev, R.A., 2012. A review of plasma-assisted methods for calcium phosphatebased coatings fabrication. Surf. Coat. Technol. 206, 2035-2056.

Thein-Han, W.W., Misra, R.D.K., 2009. Biomimetic chitosan-nanohydroxyapatite composite scaffolds for bone tissue engineering. Acta Biomater. 5, 1182-1197.
Torricelli, P., Sima, F., Axente, E., Fini, M., Mihailescu, I.N., Bigi, A., 2015. Strontium and zoledronate hydroxyapatites graded composite coatings for bone prostheses. J. Colloid Interface Sci. 448, 1-7.

VandeVord, P.J., Matthew, H.W.T., DeSilva, S.P., Mayton, L., Wu, B., Wooley, P.H., 2002. Evaluation of the biocompatibility of a chitosan scaffold in mice. J. Biomed. Mater. Res. 59, 585-590.

Visan, A., Grossin, D., Stefan, N., Duta, L., Miroiu, F.M., Stan, G.E., Sopronyi, M., Luculescu, C., Freche, M., Marsan, O., Charvillat, C., Ciuca, S., Mihailescu, I.N. 2014. Biomimetic nanocrystalline apatite coatings synthesized by Matrix Assisted Pulsed Laser Evaporation for medical applications. Mater. Sci. Eng. B 181, 56-63.

Vllasaliu, D., Casettari, L., Fowler, R., Exposito-Harris, R., Garnett, M., Illum, L., Stolnik, S., 2012. Absorption-promoting effects of chitosan in airway and intestinal cell lines: a comparative study. Int. J. Pharm. 430, 151-160.

Willershausen, I., Barbeck, M., Boehm, N., Sader, R., Willershausen, B., Kirkpatrick, C. J., Ghanaati, S., 2014. Non-cross-linked collagen type I/III materials enhance cell proliferation: in vitro and in vivo evidence. J. Appl. Oral. Sci. 22, 29-37.

Yoshida, A., Miyazaki, T., Ishida, E., Ashizuka, M., 2004. Preparation of bioactive chitosan-hydroxyapatite nanocomposites for bone repair through mechanochemical reaction. Mater. Trans. 45, 994-998.

Yu, Q., Ge, W., Atewologun, A., López, G.P., Stiff-Roberts, A.D., 2014. RIR-MAPLE deposition of multifunctional films combining biocidal and fouling release properties. J. Mater. Chem. B 2, 4371-4378.

Yuan, Q., Shah, J., Hein, S., Misra, R.D.K., 2010. Controlled and extended drug release behavior of chitosan-based nanoparticle carrier. Acta Biomater. 6, 1140-1148.

Zhang, Y., Zhang, M., 2002. Calcium/phosphate composite scaffolds for controlled in vitro antibiotic drug release. J. Biomed. Mater. Res. 62, 378-386.

Zhong, Z., Qin, J., Ma, J., 2015. Electrophoretic deposition of biomimetic zinc substituted hydroxyapatite coatings with chitosan and carbon nanotubes on titanium. Ceram. Int. 41, 8878-8884].

Zhu, Y., Zhu, R., Ma, J., Weng, Z., Wang, Y., Shi, X., Li, Y., Yan, X., Dong, Z., Xu, J., Tang, C., Jin, L., 2015. In vitro cell proliferation evaluation of porous nano-zirconia scaffolds with different porosity for bone tissue engineering. Biomed. Mater. 10, 055009 . 